\title{
Vincristine liposomes with smaller particle size have stronger diffusion ability in tumor and improve tumor accumulation of vincristine significantly
}

\author{
Siyu Ma ${ }^{1,2, *}$, Mingyuan Li ${ }^{1,3, *}$, Nan Liu ${ }^{1}$, Ying $\mathrm{Li}^{1}$, Zhiping Li ${ }^{1}$, Yang Yang ${ }^{1}$, Fanglin \\ $\mathbf{Y u}^{1}$, Xiaoqin $\mathrm{Hu}^{1,2}$, Cheng Liu ${ }^{1,2}$ and Xingguo $\mathrm{Mei}^{1}$ \\ ${ }^{1}$ Institute of Pharmacology and Toxicology, Academy of Military Medical Sciences, Beijing, PR China \\ ${ }^{2}$ Wuhan Institute of Technology, Wuhan, PR China \\ ${ }^{3}$ China International Science and Technology Cooperation Base of Food Nutrition/Safety and Medicinal Chemistry, Sino- \\ French Joint Lab of Food Nutrition/Safety and Medicinal Chemistry, Key Laboratory of Industrial Fermentation Microbiology \\ of Ministry of Education, Tianjin Key Laboratory of Industry Microbiology, College of Biotechnology, Tianjin University of \\ Science and Technology, Tianjin, PR China \\ *These authors have contributed equally to this work \\ Correspondence to: Xingguo Mei, email: ddsamms606@126.com \\ Keywords: particle size, diffusion ability, targeting effect, liposome, tumor targeting \\ Received: February 13,2017 Accepted: June 20, $2017 \quad$ Published: August 10, 2017 \\ Copyright: $\mathrm{Ma}$ et al. This is an open-access article distributed under the terms of the Creative Commons Attribution License 3.0 \\ (CC BY 3.0), which permits unrestricted use, distribution, and reproduction in any medium, provided the original author and source \\ are credited.
}

\section{ABSTRACT}

The passive targeting is the premise of active targeting that could make nanocarrier detained in tumor tissue. The particle size is the most important factor that influences the diffusion and distribution of nanoparticle both in vivo and in vitro. In order to investigate the relationship between particle size and diffusion ability, two kinds of liposome loaded with Vincristine (VCR-Lip) were prepared. The diffusion behavior of VCR-Lip with different particle size and free VCR was compared through diffusion stability study. The diffusion ability from 12-well culture plate to Millipore transwell of each formulation reflected on HepG-2 cytotoxicity results. Different cell placement methods and drug adding positions were used to study the VCR-Lip diffusion behaviors, which influenced the apoptosis of HepG-2 cell. The different cell uptake of Nile red-Lip and free Nile red was compared when changed the adding way of fluorescent fluorescein. To study the penetration ability in HepG-2 tumor spheroids, we constructed $30 \mathrm{~nm}$ and $100 \mathrm{~nm}$ Cy5.5-Lip to compare with free Cy5.5. Then the anti-tumor effect, tissue distribution of free VCR injection, $30 \mathrm{~nm}$ and $100 \mathrm{~nm}$ VCRLip were further investigated on the HepG-2 tumor bearing nude mice. The results of these study showed that the diffusion ability of free drug and fluorescent fluorescein was remarkable stronger than which encapsulated in liposomes. Moreover, diffusion ability of smaller liposome was stronger than larger one. In this way, $30 \mathrm{~nm}$ liposome had not only faster and stronger tumor distribution than $100 \mathrm{~nm}$ liposome, but also higher tumor drug accumulation than free drug as well. Our study provided a new thinking to improve the targeting efficiency of nano drug delivery system, no matter passive or active targeting. 


\section{INTRODUCTION}

In recent years, overwhelming majority of the studies on targeting drug delivery system [1] are focus on seeking new target $[2,3]$, new formulation [4], new material $[5,6]$ or more special modification $[7,8]$ to improve the targeting effect. Especially for the active targeting agent [9], this aims to enhance cellular uptake by ligands modification on the surface of nanocarrier [10]. However, the actual effects of numerous studies do not significantly improve the targeting efficiency [11]. In spite of decades of investigation, there is no active targeting nanocarrier has come into the market yet, while molecular targeting has achieved great success. One of the reasons is that they ignored the passive targeting is the basic premise of the nanocarrier taking drugs into the tumor tissue [12]. And the particle size $[13,14]$ of nanocarrier is one of the most important factors influencing the passive targeting [15], because that particle sizes could influence the in vivo behavior of nanocarrier. Generally, the anti-tumor drugs or corresponding nanocarrier were administrated by intravenous injection or intravenous infusion [16]. After getting into circulation, some drugs will bind with the plasma protein $(5 \mathrm{~nm})$ [17] and the other free drugs will quickly diffuse into tissue, and then diffuse into the space surrounding target cells. The drugs could take the therapeutic effect only when having the opportunity to contact with the cells $[18,19]$. According to the diffusion flux formula (1) [20] and the Stokes-Einstein Equation (2) $[21,22]$, we can see that the diffusion ability of nanocarrier is the most important factor to improve their antitumor effect.

$$
\mathrm{J}=-\mathrm{D} \frac{\mathrm{dc}}{\mathrm{dx}}
$$

Where $\mathrm{J}$ is diffusion flux which mean the quantity of material diffusing through the unit area per unit time, $D$ is the diffusion coefficient of particles, $d_{c}$ is the concentration gradient, the minus sign representative the diffusion direction is inverse concentration gradient.

$$
\mathrm{D}=\frac{\mathrm{RT}}{\mathrm{L}} \times \frac{1}{6 \pi \eta \mathrm{r}}
$$

Where $\mathrm{R}$ is the Boltzmann's constant, $\mathrm{T}$ is the absolute temperature, $\mathrm{L}$ is the Avogadro's number; $\eta$ is the dynamic viscosity of solution, $r$ is the radius of the spherical particle.

From these formulas above, the particle size increase will reduce the diffusion coefficient and concentration gradient. They are proportional to the diffusion flux. The nanocarrier must be firstly taken into tumor vessels by blood circulation before they enter into the tumor tissue [23]. Although there are large numbers of wide fenestration on the tumor angiogenesis [24], the nanocarriers have to overcome the elevated interstitial fluid pressure [25] and the sticky extracellular matrix [26]. All of these will weaken the diffusion effect of nanoparticles. On the other hand, the high drug loading of nanocarrier means the total number of carriers (concentration) will be reduced compare to free drug. Moreover, the diffusion coefficient of nanocarrier is much less than the drug molecular. All of these leads to less number of nanocarrier could diffuse into the tumor tissue through tumor vessels. In other words, even for the modified nanocarriers, they also depend on chance to interact with the complementary recipient and to play the active targeting role. We performed a series of related studies in vitro and in vivo to prove our hypothesis that reducing the particle size could improve tumor targeting efficient of nanocarrier.

\section{RESULTS AND DISCUSSION}

\section{Characteristics of liposome}

$100 \mathrm{~nm}$ and $30 \mathrm{~nm}$ liposomal formulations containing VCR were prepared by the film dispersion method [27,28] and reverse evaporation method [29], respectively. The particle size was determined by the laser particle analyzer and morphologically characterized by TEM. As Figure 1A and 1C showed, the large particle VCR-Lips was $100.0 \pm 2.5 \mathrm{~nm}$ and the small was $30.0 \pm 1.6$ $\mathrm{nm}$. The result also showed that the particle size measured by two different methods were consistent. The drug loading and encapsulation efficiency is summarized in Table 1. The VCR encapsulation efficiency of $100 \mathrm{~nm}$ VCR-Lips was $96.28 \pm 2.38 \%$ and the $30 \mathrm{~nm}$ ones was $94.73 \pm 5.26 \%$. And the drug loading of two kinds of VCR-Lips was $1.70 \pm 0.12 \mathrm{mg} / \mathrm{mL}$ and $1.59 \pm 0.46 \mathrm{mg} / \mathrm{mL}$, respectively.

\section{The turbiscan stability index of free VCR, 100 $\mathrm{nm}$ and $30 \mathrm{~nm}$ VCR-Lip}

We used the turbiscan $\mathrm{Lab}^{\mathrm{R}}$ Expert to evaluate the diffusion ability of different formulations in vitro. Figure $2 \mathrm{~B}-2 \mathrm{G}$ was the transmission profiles when diluted the free VCR and $30 \mathrm{~nm}$ VCR-Lip, $100 \mathrm{~nm}$ VCR-Lip formulation with mixed and unmixed method. The PBS (Figure 2A) was the blank control for other groups. The results showed that each formulation of mixing group (Figure 2B, 2D, and 2F) was no apparent aggregation or sedimentation during the scan. However, the un-mixing group showed that $100 \mathrm{~nm}$ VCR-Lip (Figure 2G) had the floating phenomenon in the early stage and sedimentation in the later period during the scanning, which mean that the larger particle size liposome could not spontaneously diffusion uniformity in $48 \mathrm{~h}$. The $30 \mathrm{~nm}$ VCR-Lip (Figure 2E) could diffuse uniformity when the scan was completed. For the free VCR solution (Figure 2C), it could rapidly reach the diffusion equilibrium. Figure 3B was the destabilization kinetics of each group. The value of destabilization kinetics could give the quantification of the diffusion equilibrium state during the scanning, 
Table 1: The entrapment efficiency and drug loading of two particle size VCR-Lip (n=3)

\begin{tabular}{lcc}
\hline Particle size $(\mathbf{n m})$ & Entrapment efficiency $(\%)$ & Drug loading(mg/mL) \\
\hline $30.0 \pm 1.6$ & $94.73 \pm 5.26$ & $1.59 \pm 0.46$ \\
$100.0 \pm 2.5$ & $96.28 \pm 2.38$ & $1.70 \pm 0.12$ \\
\hline
\end{tabular}

the smaller value of destabilization kinetics meant that the time dilution process reach the diffusion equilibrium was shorter. The $100 \mathrm{~nm}$ and $30 \mathrm{~nm}$ VCR-Lip un-mixing group have larger destabilization kinetics compared to the free VCR un-mixing group and blank control group, moreover this value increased when the particle size was larger. This prompted that the larger particle size of liposome, more difficult to diffusion equilibrium in vitro. For the destabilization kinetics of mixing groups was close to the blank control group and the free VCR solution group which had the minor value. Destabilization kinetics of mixing and un-mixing free VCR solution groups was consistent to the blank control group of PBS. This result showed that the VCR solution could get diffusion equilibrium faster than the nano formulation. For smaller size nano formulation, the time to achieve balance was shorter than the larger one. Figure $3 \mathrm{~A}$ showed the turbiscan sample bottles containing the diluted sample of each groups at the $0 \mathrm{~h}$ and $48 \mathrm{~h}$. For the mixing groups of free VCR solution, $30 \mathrm{~nm}$ VCR-lip, $100 \mathrm{~nm}$ VCR-lip and the un-mixing groups of VCR solution are uniform during scanning process in the turbiscan $\mathrm{Lab}^{\mathrm{R}}$ Expert for $48 \mathrm{~h}$. The $30 \mathrm{~nm}$ VCR-Lip of un-mixing group could reach the diffusion equilibrium after place for $48 \mathrm{~h}$. However, for the $100 \mathrm{~nm}$ un-mixing VCR-Lip group, it still did not reach diffusion equilibrium which had obvious stratification at $48 \mathrm{~h}$. This result meant that the larger liposome could not spontaneously diffuse uniform without external force. This could preliminary inference that the larger liposome maybe difficult to diffuse into the internal tumor tissue from the tumor vessels in vivo, because of the slow liquid flow formed the blood capillary in the tissues.

\section{The effect of diffusion ability on cytotoxicity}

The membrane pore at bottom of Millipore transwell is about $400 \mathrm{~nm}$. For $30 \mathrm{~nm}$ and $100 \mathrm{~nm}$ VCR-Lips, they were easy to pass through it.
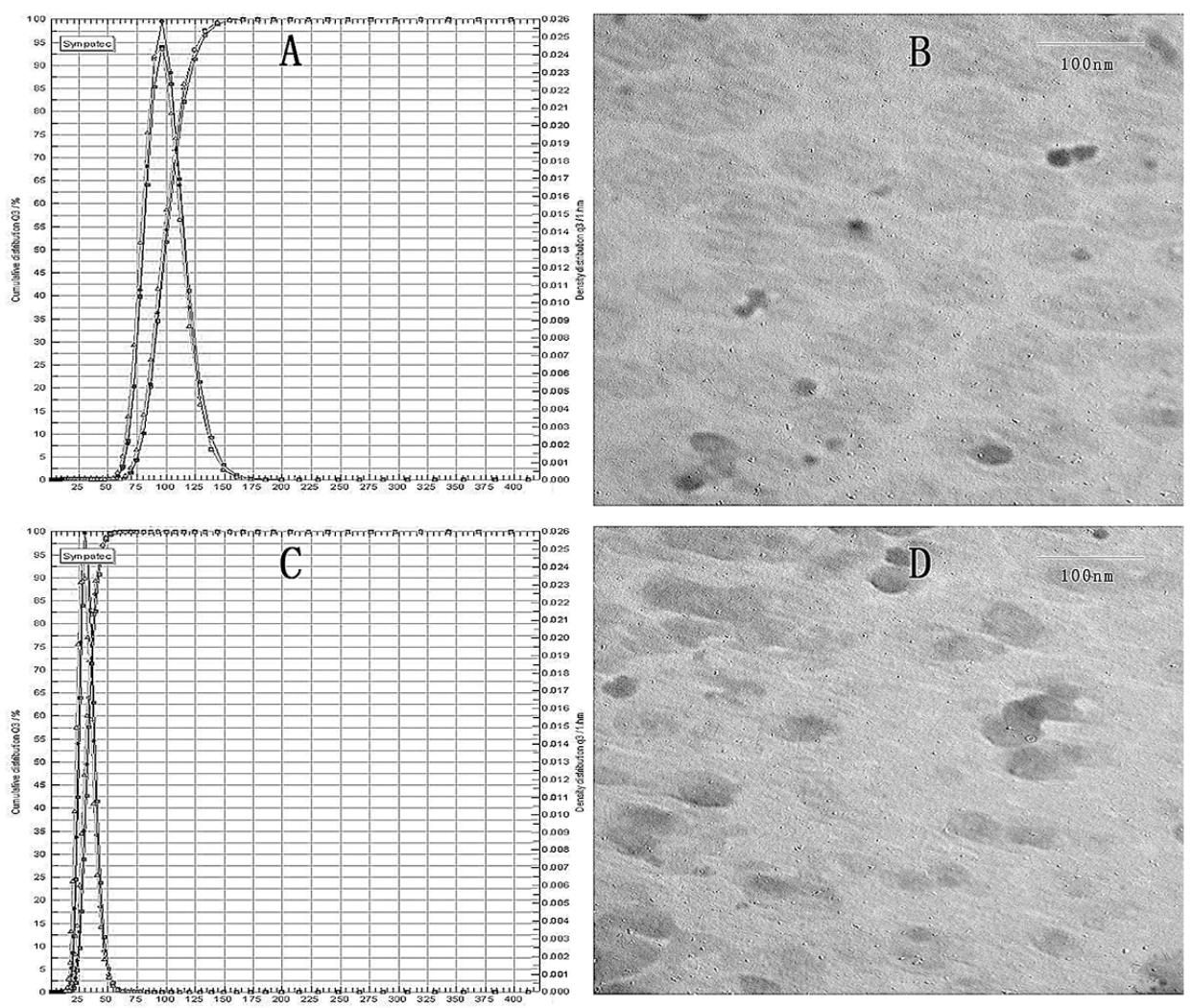

Figure 1: The Particle distribution and morphology of VCR-Lip. (A)\&(C) Particle size distribution. (B)\&(D) TEM images of two particle size of VCR-Lip. 
To study the diffusion ability of free VCR solution, $30 \mathrm{~nm}$ and $100 \mathrm{~nm}$ VCR-Lips pass through the membrane [30], these different formulations were respectively added to the inside of Millipore transwell and the 12 well-plate which was at the outside of Millipore transwell. The result was showed in the Figure 4A and 4B, which was MTT staining of the HepG-2 cells in the Millipore transwell after the cells were adopted by different VCR formulations and different VCR formulations added methods. The cell inhibition rate of the inside and outside addition of free VCR was respective $15.86 \pm 2.67 \%$ and $17.33 \pm 3.32 \%$ $(\mathrm{P}>0.05)$. For $30 \mathrm{~nm}$ VCR-Lip, the cell inhibition rate of inside addition was $88.94 \pm 10.50 \%$ and outside addition was $73.38 \pm 2.80 \%(\mathrm{P}<0.05)$. The inside addition and outside addition of $100 \mathrm{~nm}$ VCR-Lip was $97.96 \pm 4.35 \%$ and $56.49 \pm 3.14 \% \quad(\mathrm{p}<0.01)$, respectively. The result showed that no matter which addition method, free VCR solution had similar cytotoxicity, for because of the VCR molecular could diffuse pass membrane fenestrate and become uniform dispersed very quickly. For the VCR-Lip, the different cytotoxicity between the drug added way was $15.55 \%(30 \mathrm{~nm})$ and $41.47 \%(100 \mathrm{~nm})$, respectively. This result reflected the diffusion ability of passing through the membrane fenestrate from the 12 -well plates to the inside of Millipore transwell. The larger liposome was weaker than the smaller one. And the two drugs addition ways of $100 \mathrm{~nm}$ VCR-lip showed an obvious difference. The poor diffusion ability of $100 \mathrm{~nm}$ VCR-lip could lead
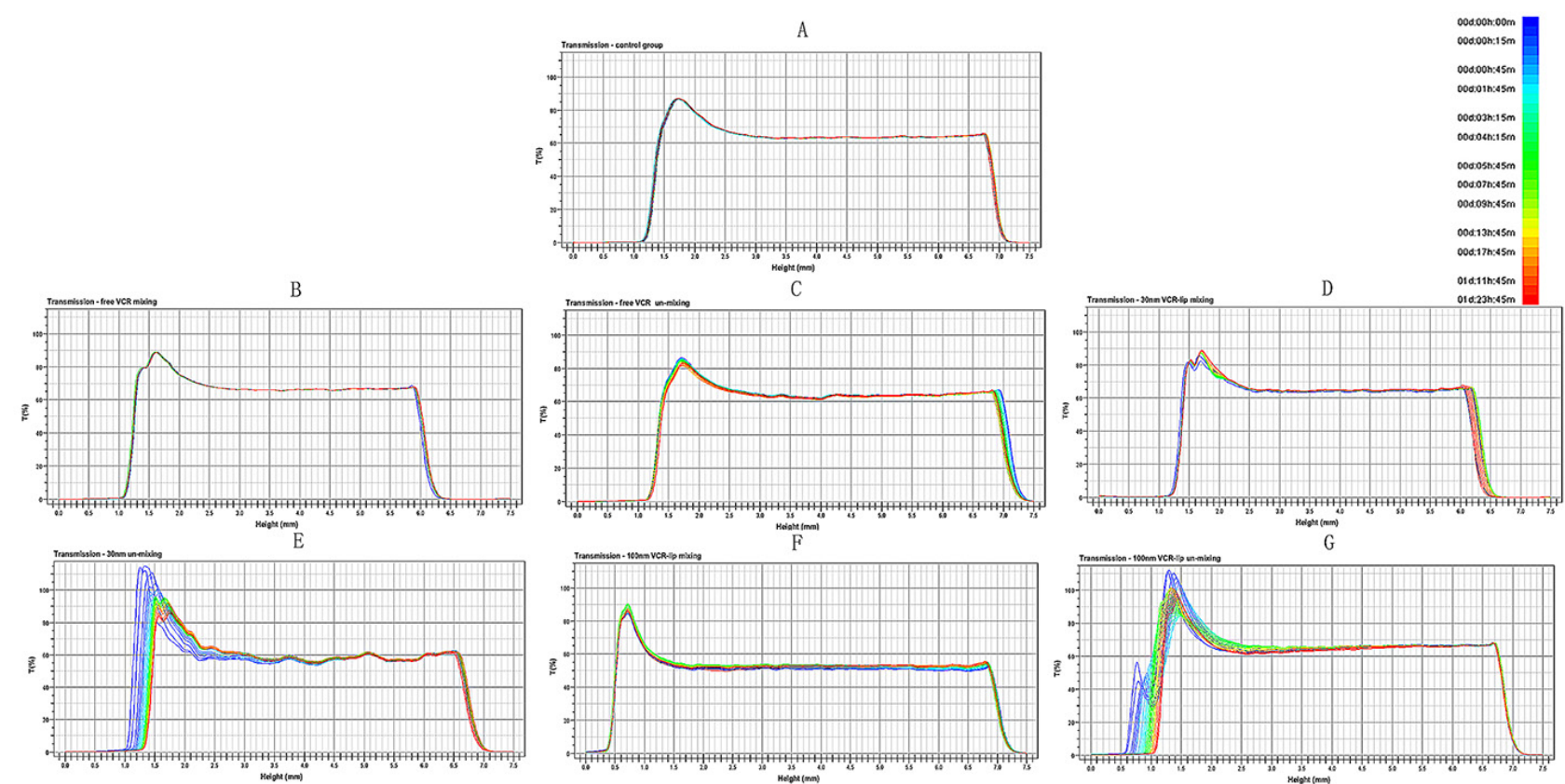

Figure 2: The process of preparation diffusion when dilution with PBS. (A). The PBS blank control. (B)\&(C) The mixing and unmixed of free-VCR. (D)\&(E) The mixing and unmixed of 30nm VCR-Lip. (F)\&(G) The mixing and unmixed of 100nm VCR-Lip.
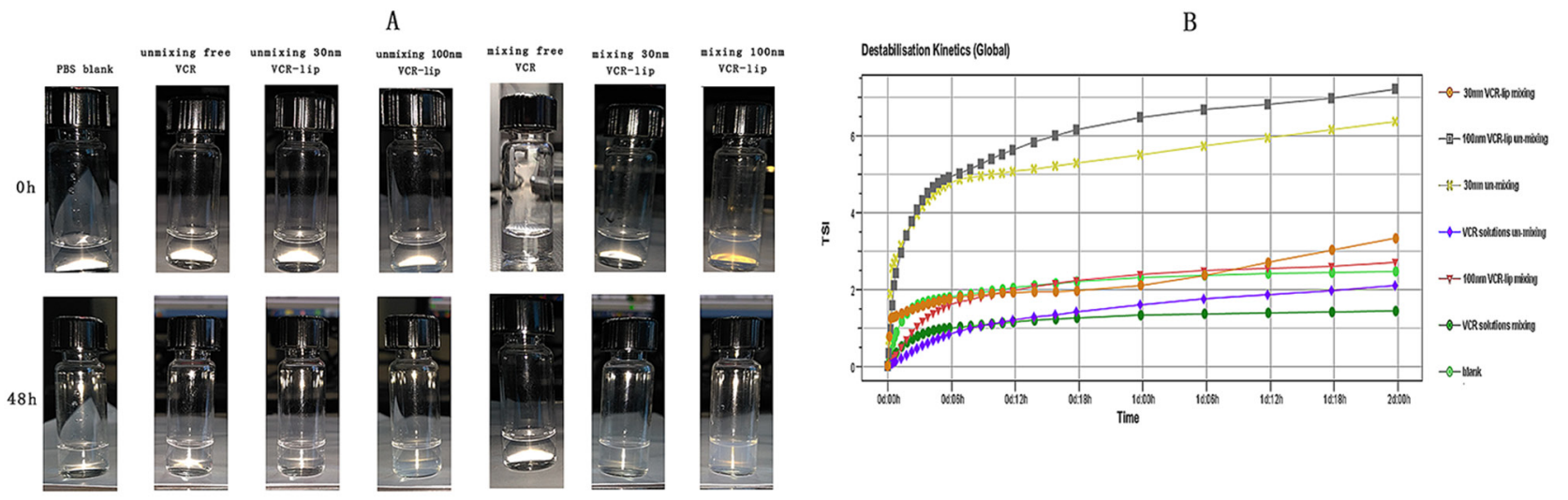

Figure 3: The turbiscan stability of free VCR, $100 \mathbf{~ n m}$ and $30 \mathrm{~nm}$ VCR-Lip. (A) The diffusion state of different VCR-Lip and free VCR in turbiscan sample bottles. (B) The destabilization kinetics of each mixing and unmixed group. 
diffusion nonuniform and the high local concentration lead abundant of the cell death.

\section{Diffusion in the crosslinked agar}

To further proved the different diffusion ability of the free vincristine molecular and VCR-Lip with different particle size distribution in the tree-dimensional crosslinked medium [31,32], the size of HepG-2 cells inhibition zone in agar plate was compared. Figure 5A and $5 \mathrm{~B}$ was the results of control group, free VCR, $30 \mathrm{~nm}$ VCR-Lip and $100 \mathrm{~nm}$ VCR-Lip diffusion and permeation from the oxford cup into agar to kill the HepG-2 cells. The cell inhibition area of free VCR solution, $30 \mathrm{~nm}$ VCR-Lip and $100 \mathrm{~nm}$ VCR-Lip appears a decreasing trend. The relative growth inhibition area of HepG-2 cells (Figure $5 \mathrm{~B}$ ) in turn is $769.23 \pm 59.84 \%$, $499.41 \pm 29.77 \%$ and $185.49 \pm 27.66 \%$. This result meant the diffusion ability was decreasing as the particle size increased. The results of diffusion in agar showed the ability of diffusion and permeation in the cross-linked agar from strong to weak was as below: free drug, $30 \mathrm{~nm}$ VCR-Lip and $100 \mathrm{~nm}$ VCR-Lip. In the other word, reduced the particle size could improve the diffusion ability in the crosslinked medium.

\section{Diffusion effect on apoptosis}

The different placement methods of cell plated slide could affect the contact between formulations and cells. Figure 6 was the apoptosis rate of different formulations after incubation with the HepG-2 cell plated slide for different placement methods. The normal survival cell rate of the placed upwards control group, the placed down control group, the placed down $30 \mathrm{~nm}$ VCR-Lip group and the placed down $100 \mathrm{~nm}$ VCR-Lip group was $90.1 \%, 90.0 \%, 88.7 \%$ and $90.4 \%$, respectively. These groups showed a lower value of cytotoxicity. However, for placed down free VCR group this rate was $73.5 \%$. These values proved when place down the cell plated slide, the nanocarriers cannot diffuse to the cell side of slide and act with cells, but the free VCR could. This conclusion could be proved by the difference of cell survival rate between the place up and place down culture group (Figure 6B). This value of each group was $6.5 \%$ (free VCR), $25.1 \%$ (30 nm VCR-Lip), 44.4\% (100 nm VCR-Lip). The difference value was increased along with the enlarge of nanoparticle size (diffusion ability). The left upper quadrant of $100 \mathrm{~nm}$ VCR-Lips group was obvious

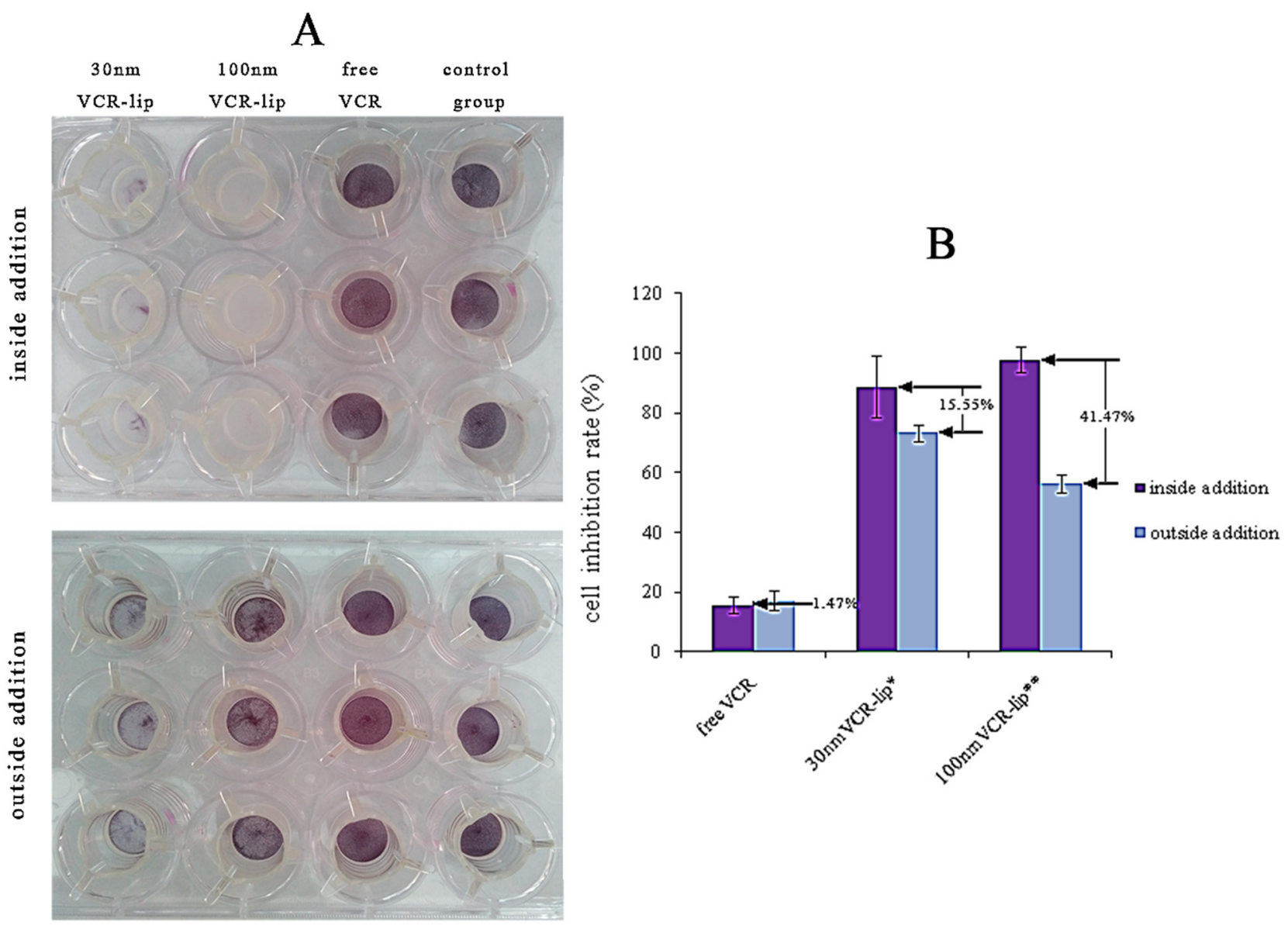

Figure 4: The different of preparation and drug added methods influence the cytotoxicity. (A) The cell survival rate in Millipore transwell after added drug for $24 \mathrm{~h}$. (B) The cell inhibition rate of each group. 
increased, for the local high concentration caused the cytoclasis. The region of $30 \mathrm{~nm}$ VCR-Lips group was significantly reduced (Figure 6A). This results further validated the larger particle size liposome had a weaker diffusion ability, which led to the significant difference after changing the placement methods. However, the small molecular VCR could easily diffuse to reaching uniformity in the culture solution and act with the cell on the slide. This meant that reduced the particle size of carriers could increase the diffusion ability and improve the contact opportunity of cells and carriers.

\section{The different diffusion ability influenced cell uptake}

To investigate the diffusion behavior in the horizontal direction, we used two addition methods of fluorescein: one was adding fluorescein (or fluorescence labeling liposome) right above of the cells; the other was adding fluorescein (or fluorescence labeling liposome) at the position which was away from the cells. Figure 7 was the results of cell uptake for free NR, $30 \mathrm{~nm}$ NR-lip, and $100 \mathrm{~nm}$ NR-lip. The fluorescence intensity of each
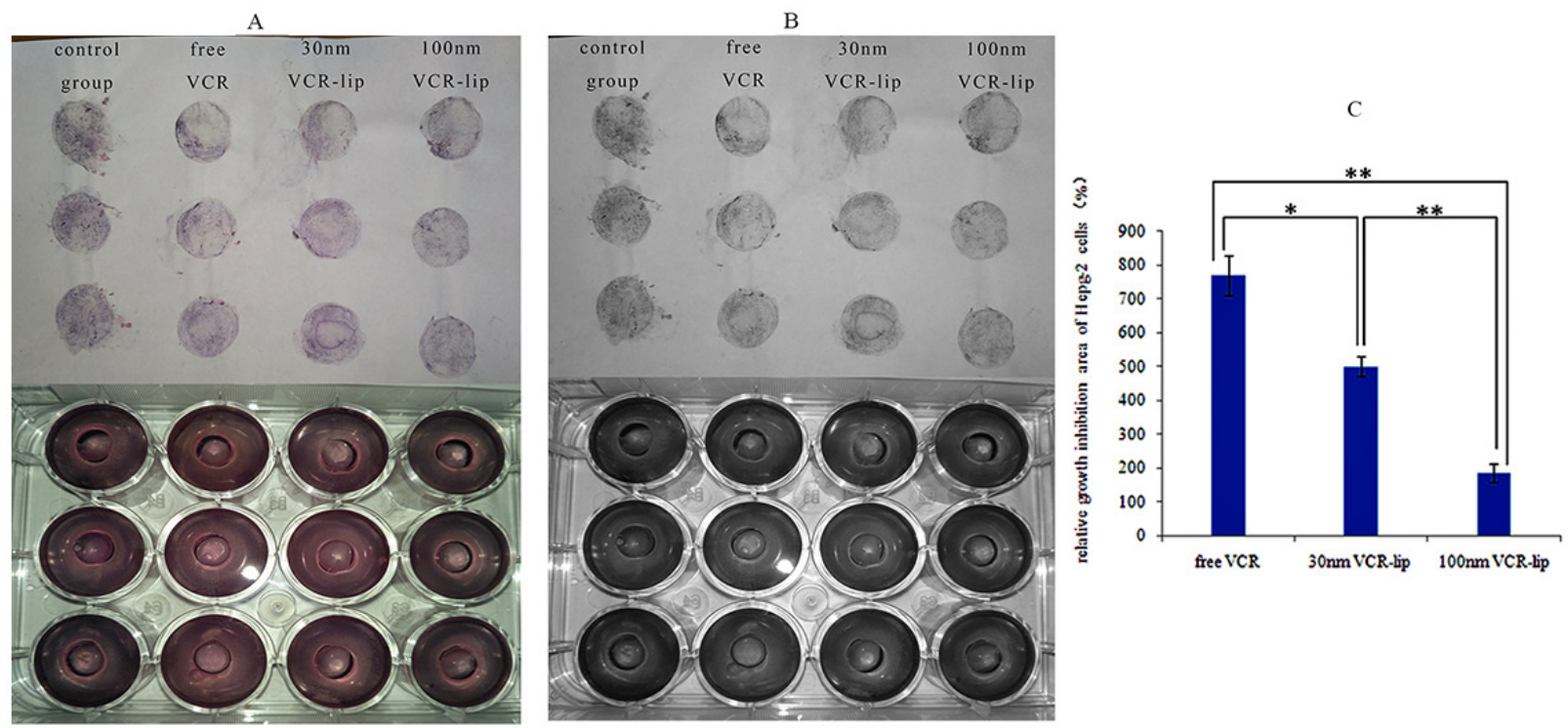

Figure 5: The cells growth inhibition area of different VCR-Lip and free VCR. (A) The RGB of agar plate and transfer diagram. (B) The grey-scale map of agar plate and transfer diagram. (C) The relative growth inhibition area of HepG-2 cells.

A
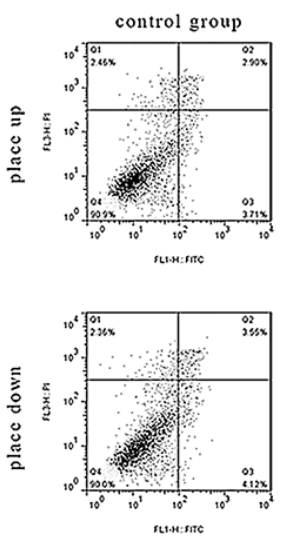
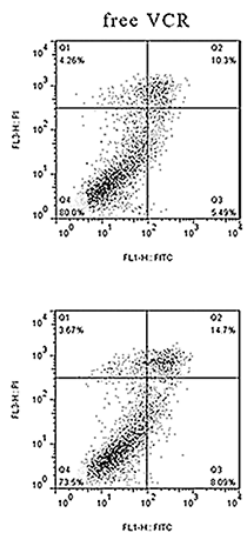
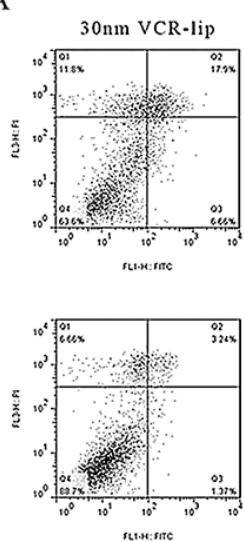

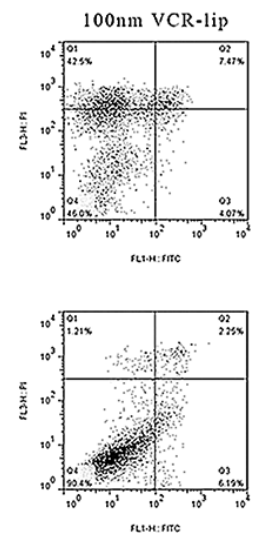

B

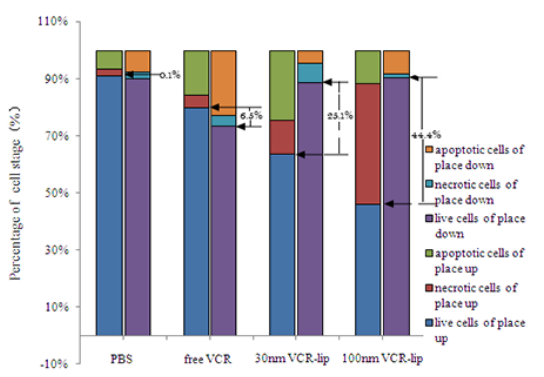

Figure 6: The influence of different placement methods for cells plated slide on cell apoptosis. (A) The two-dimensional scatter diagram of flow cytometry. (B) The percentage of cell stage in each group. 
fluorescein added right above cells group was increased with the increasing of formulation particle size. But for groups with fluorescein added a distant away from the cells, the fluorescence intensity was significantly weakened with the particle size increasing. Moreover, the molecular fluorescein added way did not affect cell uptake. This result was due to the free fluorescein could diffusion uniform in a short time. While, the fluorescence labeling liposome needed long time to diffusion and acted with cells. Thus, we had a conclusion that the diffusion ability of the larger particle size liposome is weaker than the smaller one in horizontal direction and in vitro.

\section{The penetration into the tumor spheroids}

Figure 8 was the CLSM results of the free Cy5.5, 30 $\mathrm{nm}$ Cy5.5-Lip and $100 \mathrm{~nm}$ Cy5.5-Lip penetrating through the tumor spheroids in vitro. The free Cy5.5 and $30 \mathrm{~nm}$ Cy5.5-Lip encapsulated fluorescein had strong penetration ability in tumor spheroids. And the penetration ability of $30 \mathrm{~nm}$ Cy5.5-Lip was even stronger than the free Cy5.5. We inferred this reason was that the diffusion ability of fat soluble Cy5.5 fluorescein was weak in the culture solution. The free Cy5.5 fluorescein was more easily to accumulate on the surface cells of tumor spheroids, before it penetrated into the inside of tumor spheroids. Because of the larger size Cy5.5-Lip was more difficult to penetrate into the inside of tumor spheroids than the smaller one. In this way, the larger Cy5.5-Lip only showed deeper dying on the outer layer of tumor spheroids. The tumor spheroids penetration test result shown that the small particle size Cy5.5-Lip was easier penetrating into the inside of tumor spheroids, for the higher diffusion ability of it.

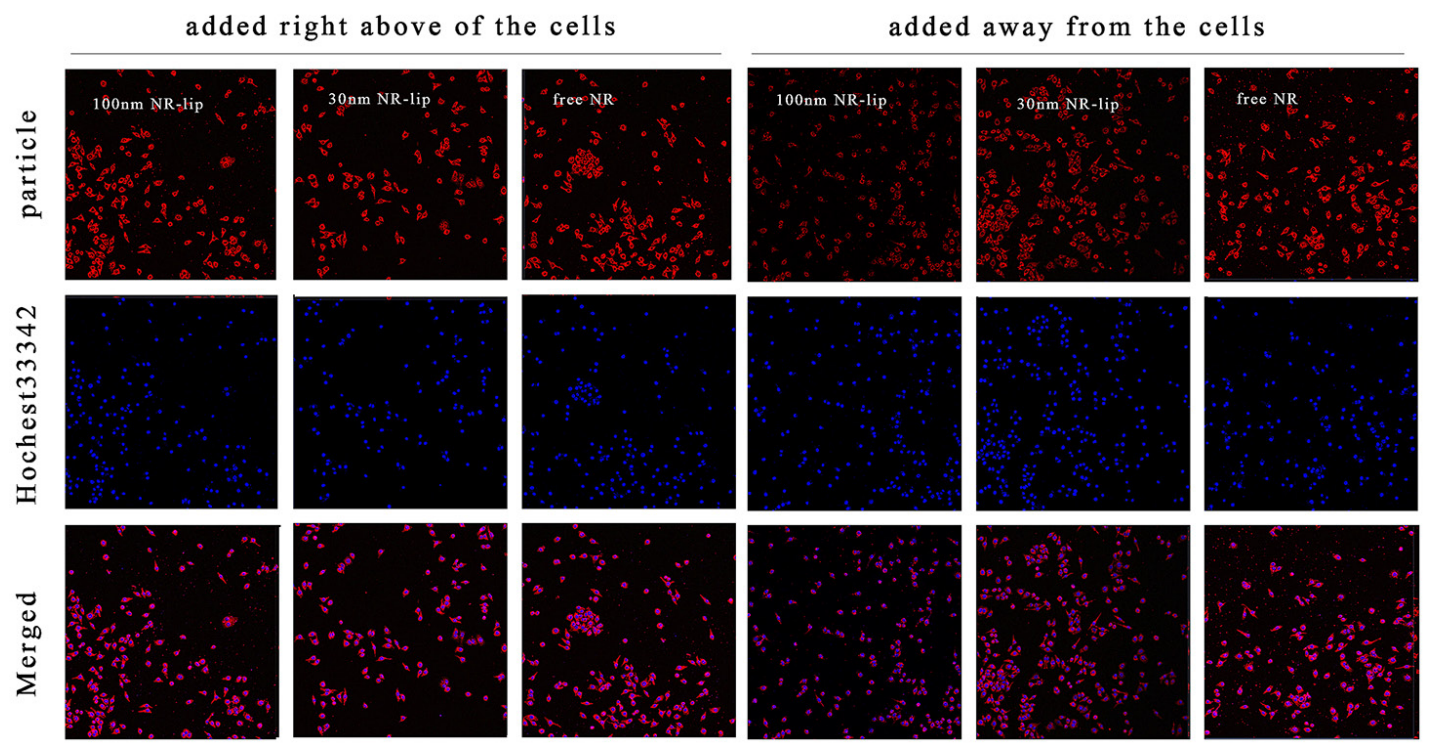

Figure 7: The cell uptake of different dyestuff added methods for free NR, $30 \mathrm{~nm}$ NR-lip, and $100 \mathrm{~nm}$ NR-Lip with CLSM.

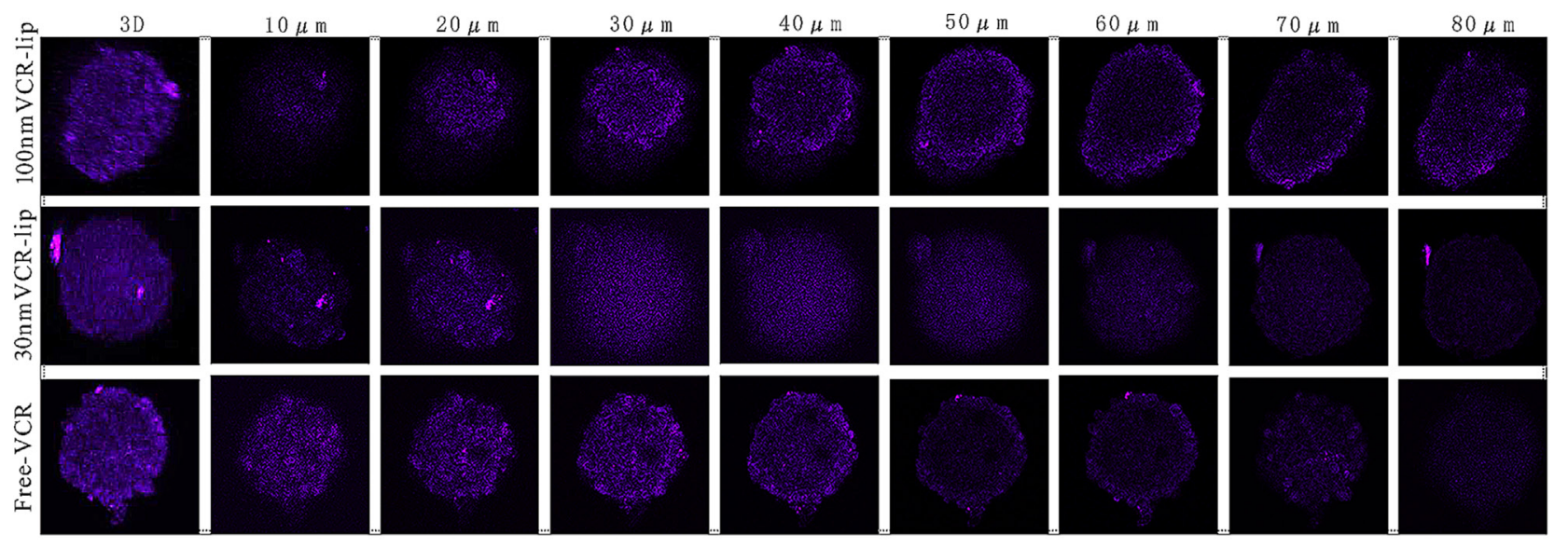

Figure 8: The different particle size Cy5. 5-Lip and free Cy5.5 penetrated into the tumor spheroids. 
Table 2: The tumor inhibition rate of $100 \mathrm{~nm}$ VCR-Lip, free VCR and $30 \mathrm{~nm}$ VCR-Lip treatment groups

\begin{tabular}{lccc}
\hline Preparation & 100nm VCR-Lip & Free VCR & 30nm VCR-Lip \\
\hline Tumor inhibition rate (\%) & $51.53 \pm 10.23^{* *}$ & $71.24 \pm 8.15^{*}$ & $79.31 \pm 9.56$ \\
\hline
\end{tabular}

“**” mean the $\mathrm{p}$ value of tumor inhibition rate between the free VCR group and $30 \mathrm{~nm}$ VCR-Lip was less than 0.05 ; “**” mean the $\mathrm{p}$ value of tumor inhibition rate between the 100nm VCR-Lip group and the other two groups was less than $0.01, \bar{x} \pm s$, $\mathrm{n}=6$.

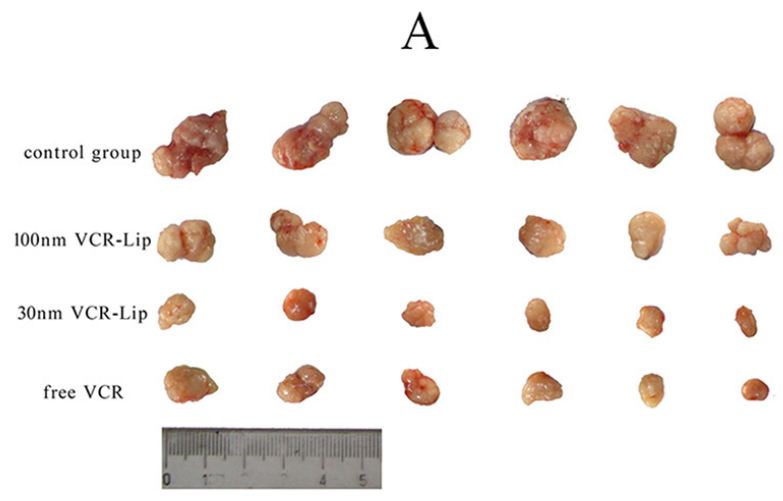

B
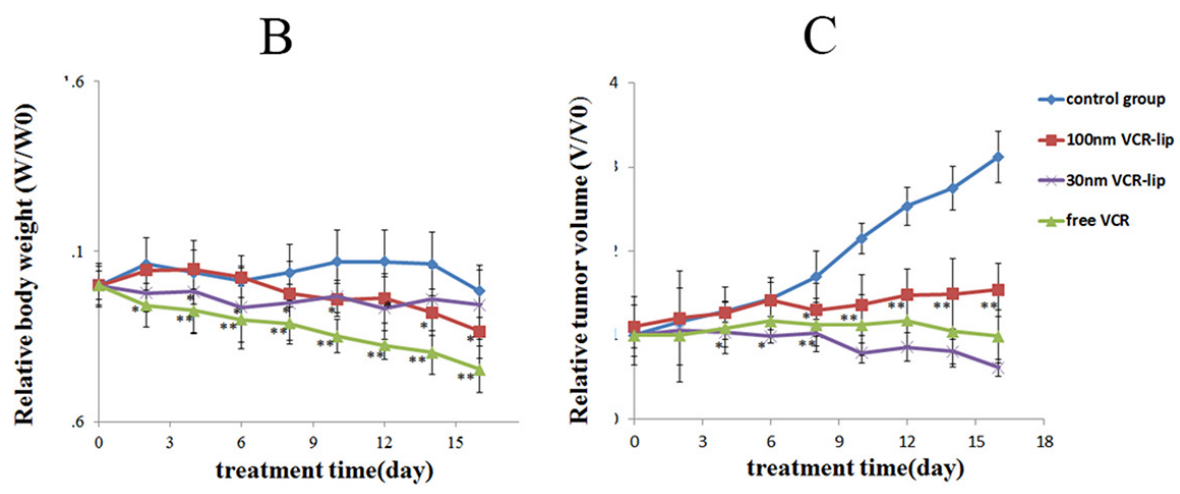

Figure 9: The anti-tumor effect of free VCR, $30 \mathrm{~nm}$ VCR-Lip and $100 \mathbf{~ n m ~ V C R . ~ ( A ) ~ T h e ~ t u m o r ~ o f ~ t r e a t m e n t ~ g r o u p s ~ a n d ~}$ control group. (B) The relative body weight of each group. (C) The relative tumor volume of each group.
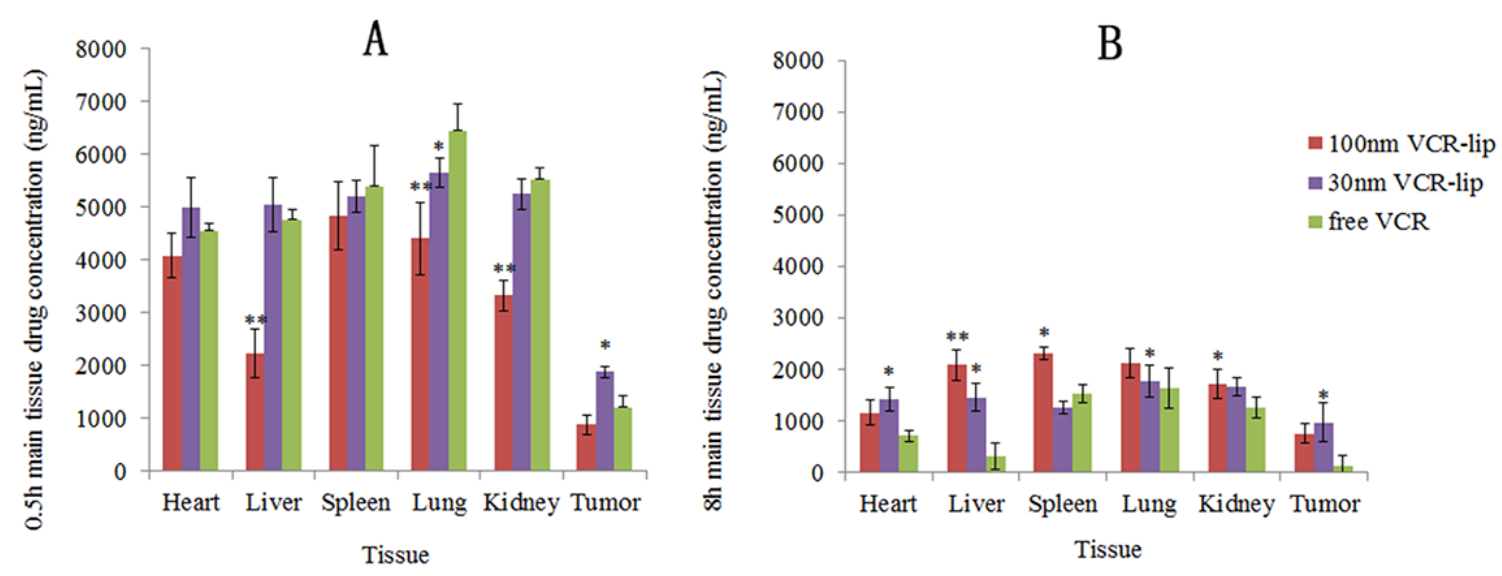

Figure 10: The VCR concentration in major tissues. (A) The drug concentration of main tissues at $0.5 \mathrm{~h}$. (B) The drug concentration of main tissues at $8 \mathrm{~h}$. 


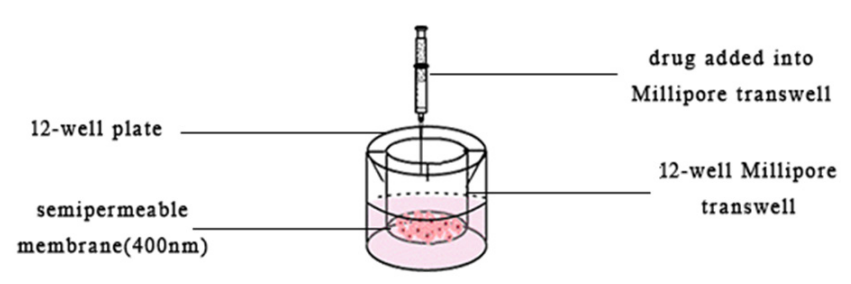

B

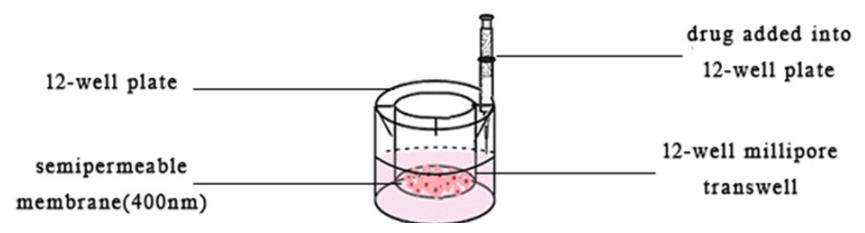

Figure 11: The schematic diagram of drug added methods. (A) Added the drug into the Millipore transwells. (B) Added the drug into 12 -well plate.

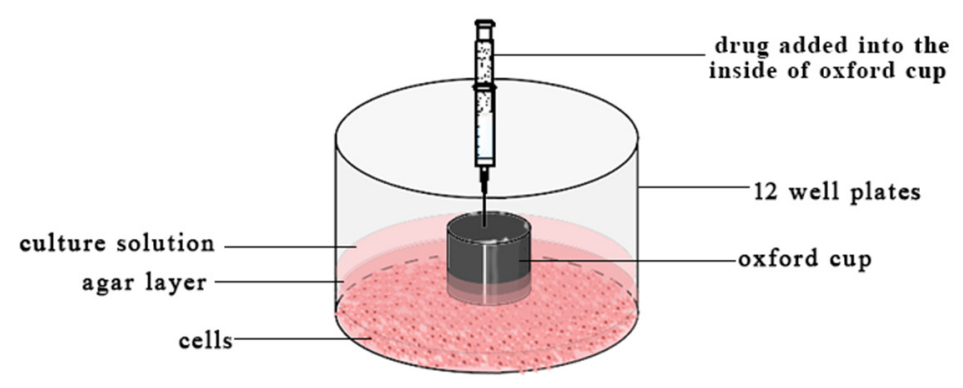

Figure 12: The schematic diagram of diffusion in the agar plate.

A

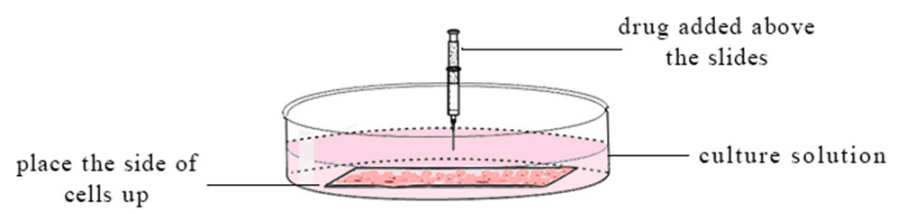

B

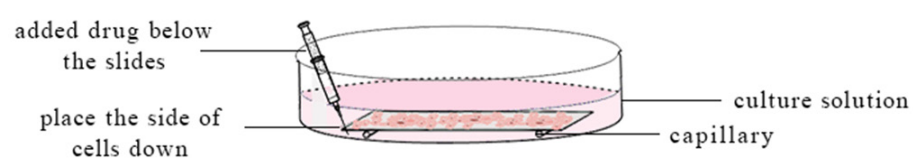

Figure 13: The schematic diagram of different slide placement and drug added methods. (A) The cells side of slides was placed up and added drug on it. (B) The cells side of slides was placed down and added drug below it. 
Table 3: Program of gradient elution

\begin{tabular}{lcc}
\hline Time(min) & Mobile phase A:B & Flow rate (ml/min) \\
\hline 0.0 & $40: 60$ & 0.4 \\
0.2 & $0: 100$ & 0.4 \\
1.48 & $0: 100$ & 0.4 \\
1.5 & $40: 60$ & 0.4 \\
5.0 & $40: 60$ & 0.4 \\
\hline
\end{tabular}

\section{Anti-tumor effect}

The weight change of mice could reflect the toxicity of treatments [33] and the anti-tumor effect was reflected by the changes of tumor volume [30]. As shown in Figure 9B, the relative body weight of each treatment group decreased. The most significantly declined group was the free VCR group $\left(0.753 \pm 0.081, \mathrm{~m} / \mathrm{m}_{0}\right)$. The relative body weight of $30 \mathrm{~nm}$ VCR-Lip group decreased during the early stage of treatment, but increased in the advanced stage. The body weight of $100 \mathrm{~nm}$ VCR-Lip group was in the opposite trend with the $30 \mathrm{~nm}$ VCR-Lip group. The results indicated the free VCR and $30 \mathrm{~nm}$ VCR-Lip was more easily to enter into the tissues. For the stronger diffusion ability from blood to tissue, they showed obvious weight loss in the early stage. However, with the tumor progression, the weigh was loosed by tumor cachexia. Because of the high diffusion ability and cell affinity, more $30 \mathrm{~nm}$ VCR-Lip could enter into the tumor tissue and cells to play the antitumor effect. Although the free VCR had sufficient diffusion ability, it was metabolized and excreted out of body very quickly, so the antitumor effect of free VCR was weaker than the $30 \mathrm{~nm}$ VCR-Lip. For the larger VCR-Lip, they were more difficulty to diffuse into major organs or tissues [31], and most of them were swallowed by the phagocytes [33] in the liver and spleen. As shown in Figure 10B, the VCR concentration of $100 \mathrm{~nm}$ VCR-Lip in liver and spleen was relatively higher than the free VCR and $30 \mathrm{~nm}$ VCRLip. The relative tumor volume change was shown in the Figure 9C; the trend of $30 \mathrm{~nm}$ VCR-Lip group was consistent with the free VCR group, and both of them were decline. However, the relative tumor volume of 100 nm VCR-Lip group and control group was increased. The final tumor inhibition rate shown in Table 2 also was given the same results. There was significant difference between the $30 \mathrm{~nm}$ VCR-Lip and free VCR group $(\mathrm{P}<0.05)$. On contrary, the free VCR group and $100 \mathrm{~nm}$ VCR-Lip had an extremely significant difference $(\mathrm{P}<0.01)$, as well as $30 \mathrm{~nm}$ VCR-Lip and $100 \mathrm{~nm}$ VCRLip. In summary, the anti-tumor effect showed that the smaller VCR-Lip had strong antitumor effect in vivo same as the free VCR and the lower toxicity, because of the stronger diffusion ability.

\section{Tissue distribution in vivo}

Figure 10 was the major tissue distribution of free VCR, $30 \mathrm{~nm}$ VCR-Lip and $100 \mathrm{~nm}$ VCR-Lip group after tail vein injection for $0.5 \mathrm{~h}$ (Figure 10A) and $8 \mathrm{~h}$ (Figure 10B). The VCR concentration in various tissues of the free VCR group was higher at $0.5 \mathrm{~h}$, but the VCR concentration in tumor was lower than the $30 \mathrm{~nm}$ VCRLip group and higher than $100 \mathrm{~nm}$ VCR-Lip. For other tissues, $100 \mathrm{~nm}$ VCR-Lip group was the lowest. After distribution and excretion for $8 \mathrm{~h}$, the VCR concentration in various tissues for each group decreased (Figure 10B). The VCR concentration of $100 \mathrm{~nm}$ VCR-Lip group in various tissues was relatively higher than other groups. But in tumor, the VCR concentration of $30 \mathrm{~nm}$ VCRLip was the highest. The results of tissue distribution determination showed that with the decreasing of particle size, the quantity of drug entering into tissues increased in the short time. Because of the good diffusion ability of small molecule and smaller particle size VCR-Lip. As time went on, the drug accumulation in tissues of free drug showed obvious decline. And the $100 \mathrm{~nm}$ VCR-Lip obviously accumulated in the tissues which contained a large number of phagocyte cells [34]. For the $30 \mathrm{~nm}$ VCRLip group, the VCR concentration in the major tissue was lower than the $100 \mathrm{~nm}$ VCR-Lip group and close to the free VCR group. In tumor, the $30 \mathrm{~nm}$ VCR-Lip group showed stronger diffusion ability and better retention effect for the EPR effect. The tissue distribution results verified the viewpoint that decreasing particle size of nanocarriers could increase their diffusion ability which leaded to the closer distribution behavior with the free drug, and then they could diffuse into tumor tissue from the gap of angiogenesis. In addition, the smaller liposome also kept characteristics of liposome such as the strong retention effect [35], high cell affinity and modifiability.

\section{MATERIALS AND METHODS}

\section{Reagents}

Dipalmitoyl phosphatidylcholine (DPPC), 1,2-distearyl-sn-glycero-3-phosphoethanolamine -N[methoxy(polyethylene glycol)-2000] (DSPE-PEG ${ }_{2000}$ ) 
and Monostearoyl phosphatidylcholine (MSPC) were purchased from Xi" an ruixi Biological Technology Co., Ltd, China. Vincristine sulfate (VCR, purity >99\%) was bought from Min Sheng pharmaceutical group Co., Ltd, China. Dulbecco's Modified Eagle Media (DMEM) was bought from Gibco by Thermo Fisher Scientific, China. Agarose (low gelling temperature), Hochest33258, Cy5.5 and Nile red was bought from Aldrich of Sigma Co., Ltd, USA. Trypsin was purchased from solarbio. Fetal bovine serum (FBS) was bought from Zhejiang Tianhang Biotechnology Co., Ltd, China. Thiazolyl Blue Tetrazolium Bromide (MTT), Annexin V-FITC/PI Apoptosis Detection Kit was bought from GL Biochem Co., Ltd, Shanghai, China.

\section{Cells and animals}

HepG-2 cells were kindly provided by the Drug Metabolism Department (Beijing Institute of Pharmacology and Toxicology). Nude mice (18-22g, q) were purchased from Vital River Laboratories (Beijing, China). All animal experiments were performed under a protocol approved by Henan laboratory animal center.

\section{Formulation and characterization of VCR- Liposome}

\section{Formulation of blank liposome}

$100 \mathrm{~nm}$ liposome was prepared [36,37] as following: DPPC: MSPC: DSPE-PEG ${ }_{2000}$ in a mass ratio of $85: 10: 5$ were dissolved in chloroform, the solution was dried by solvent evaporation and formed the thin film on drying by vacuum desiccators. Then the phospholipids were hydrated to become multilamellar vesicles (MLVS) by the pH4.0 sodium tartaric buffer for $30 \mathrm{~min}$. These MLVS were sonicated with a cell crusher to obtain small unilamellar vesicles. The $30 \mathrm{~nm}$ liposome was prepared [38] as following: The phospholipids (same mass ratio with the $100 \mathrm{~nm}$ liposome) were dissolved in absolute alcohol at $50^{\circ} \mathrm{C}$ and $\mathrm{pH} 4.0$ sodium tartaric buffer were added into this solution. The alcohol was removed by solvent evaporation. This lipid solution was sonicated with a cell crusher until the lipid solution become clear and transparent. The residual alcohol was removed by dialysis which molecular weight cutoff was 100, 000 Daltons. The final concentration of phospholipids (100 nm and $30 \mathrm{~nm}$ liposome) was $100 \mathrm{mg} / \mathrm{ml}$.

\section{VCR encapsulated liposome}

The $\mathrm{pH}$ gradient active loading method [39] was used to contain VCR into liposome. The VCR and sucrose was dissolved in the pH4.0 sodium tartaric buffer. Then the blank liposome was added into this solution, and the sodium carbonate solution $(0.3 \mathrm{M})$ was used to regulate the $\mathrm{pH}$ to 7.4-7.5. The theoretical drug loading was about $2 \mathrm{mg} / \mathrm{ml}$.

\section{Characterization of VCR-Liposome}

\section{Particle distribution and morphology of liposome}

The particle distribution of these two liposomes was determined by photo correlation spectroscopy (Nanophox, Sympatec $\mathrm{GmbH}$, Germany) at $25^{\circ} \mathrm{C}$. The VCR-Lip was diluted 20 times by water.

The morphology of two kinds of VCR-Lip was observed by a transmission electron microscope (TEM, HITACHI, H-7650, Japan). Briefly, the VCR-Lip was diluted 35 times by water and dropped it on copper grid at room temperature. The dried copper grid was stained by $2 \%$ phosphotungstic acid and then observed by TEM.

\section{Determination of drug loading and encapsulation efficiency}

The ultra-filtration centrifugation [40] was used to determination the drug loading and encapsulation efficiency. The un-encapsulation VCR concentration was determination as following: The VCR-Lip was diluted 10 times by water and centrifuged by ultra-filtration centrifuge tube (molecular weight cutoff was 50, 000 Daltons) at $10,000 \mathrm{~g}$ for $15 \mathrm{~min}$. The filtrate in tube was the un-encapsulation VCR solution. The total VCR concentration sample was determined as following: The equal volume VCR-Lip and 5\% twelve alkyl sodium sulfate (SDS) was mixed. The mixed solution was diluted 5 times by water and then heating it until solution clear and transparent at $50^{\circ} \mathrm{C}$. The solution was used the same treatment method as the un-encapsulation VCR. The sample of un-encapsulation VCR and total VCR concentration of liposome was determination by HPLC.

The chromatographic column was ZORBAX SBC8 $(4.6 \times 250 \mathrm{~mm}, 5 \mu \mathrm{m})$, the mobile phase was methanol and diethylamide solution (pH7.0) and the proportion was 70:30. The UV (Hitachi L-2400) detection wave length was $297 \mathrm{~nm}$, the sample volume was $20 \mu \mathrm{L}$, the column temperature was $30^{\circ} \mathrm{C}$.

The entrapment efficiency (EE \%) was calculated as the following equations:

$$
\mathrm{EE} \%=\frac{\mathrm{c}_{\text {total drug }}-\mathrm{c}_{\text {free drug }}}{\mathrm{c}_{\text {total drug }}} \times 100 \%
$$

Where $\mathrm{C}_{\text {total drug }}$ and $\mathrm{C}_{\text {free drug }}$ were the total drug concentration and the un-encapsulation free drug.

\section{The turbiscan stability index of free VCR, $100 \mathrm{~nm}$ and $30 \mathrm{~nm}$ VCR-Lip during dilution}

Three sample bottles of turbiscan [41] was respectively added $900 \mu \mathrm{L}$ PBS. Then $100 \mu \mathrm{L}$ of $30 \mathrm{~nm}$ VCR-Lip, $100 \mathrm{~nm}$ VCR-Lip and $2 \mathrm{mg} / \mathrm{ml}$ free VCR (dissolution by PBS) was respectively inject into the bottom of the sample bottles. Taking the other three sample bottles, each bottle was added $900 \mu \mathrm{L}$ PBS and 
$100 \mu \mathrm{L}$ VCR-Lip or free VCR, mixing the solution. Then the last bottle was added $1000 \mu \mathrm{L}$ PBS as blank control group. All of the samples were scanned by turbiscan $\mathrm{Lab}^{\mathrm{R}}$ at $37^{\circ} \mathrm{C}$. The scanning time was $0 \mathrm{~h}, 0.5$ h, 0.75 h, 1 h, 2 h, 4 h, 8 h, 12 h, 16 h, 20 h, 24 h, 30 h, $36 \mathrm{~h}$, and $48 \mathrm{~h}$.

\section{The effect of diffusion on cytotoxicity}

$150 \mu \mathrm{L}$ DMEM suspension contained $1.5 \times 10^{6}$ HepG-2 cells was added in the 12-well Millipore transwell [42] and $825 \mathrm{ml}$ DMEM culture medium was added in the 12 well-plate. The plate was incubated overnight (Figure 11). Then the tanswells were divided into two groups. One was added $25 \mu \mathrm{L}$ free VCR $(2 \mathrm{mg} / \mathrm{mL})$, $30 \mathrm{~nm}$ VCR-Lip, $100 \mathrm{~nm}$ VCR-Lip (n=3) was respectively added into the tanswell (Figure 11A), and the other groups was respectively added into the bottom of 12-well plate (Figure 11B). The plate was incubated for $24 \mathrm{~h}$, followed by add $100 \mu \mathrm{L} \mathrm{MTT}(5 \mathrm{mg} / \mathrm{mL})$ and continued to incubate for $4 \mathrm{~h}$. The bottom membrane of each tanswell was taken off and dissolved by $0.4 \mathrm{ml}$ DMSO. Optical absorbance was determined at $492 \mathrm{~nm}$ with microplate reader. The cell inhibition rate was calculated as the follow equation (4).

$$
\text { Cell inhibition rate }=\left(1-\frac{c-c_{b}}{c_{0}}\right) \times 100 \%
$$

Where $\mathrm{C}$ was the optical absorbance of drug experimental groups, $\mathrm{C}_{\mathrm{b}}$ was the optical absorbance of zero adjusting, $\mathrm{C}_{0}$ was the optical absorbance of control group.

\section{Diffusion in the agar plate}

$2 \times 10^{5} /$ well HepG-2 cells suspension was added in the 12 well-plate and incubated overnight. The supernatant of each well was discarded and added $0.3 \mathrm{~mL} 2 \%(\mathrm{w} / \mathrm{w})$ hot agar-DMEM [43] solution. When the agar was coagulation, the oxford cups (internal $5.8 \mathrm{~mm}$, external diameter $7.90 \mathrm{~mm}$ ) were put on the agar plate. And 0.2 $\mathrm{mL}$ agar solution was added outside of the oxford cups to fix it. Then $0.3 \mathrm{~mL}$ DMEM culture medium was added in the outside of the oxford cups and $0.1 \mathrm{~mL}$ of $0.2 \mathrm{mg} /$ $\mathrm{mL}$ free VCR, $30 \mathrm{~nm}$ VCR-Lip, 100 nm VCR-Lip, PBS was respectively added into the inside of oxford cups $(n=3)$ as Figure 12. The plate was incubated for $24 \mathrm{~h}$ at $37^{\circ} \mathrm{C}$, followed by removing the oxford cups. Discard the supernatant and washed twice by PBS. Each well was added $270 \mu \mathrm{L}$ DMEM culture medium and $30 \mu \mathrm{L}$ MTT and incubated for $4 \mathrm{~h}$ at $37^{\circ} \mathrm{C}$. Then the plate was washed twice by PBS and measures the diameter of each cells inhibition zone. The agar was taken out and put on the white cardboard to transfer the print of inhibition zone. The relative growth inhibition area of HepG-2 cells (RA) as follow (5).

$$
\mathrm{RA}=\frac{\mathrm{S}-\mathrm{S}_{0}}{\mathrm{~S}_{0}} \times 100 \%
$$

Where $\mathrm{S}$ is the inhibition area of drug added group, $\mathrm{S}_{0}$ is the inner ring area of oxford cup.

\section{The influence of diffusion ability on cell apoptosis}

$1 \mathrm{~mL}$ HepG-2 cells suspension contained $5 \times 10^{6}$ cells was coated on the slide and incubated for $8 \mathrm{~h}$. These slides were divided two groups. In one group, the cells side of slides was placed upside down and put on the capillaries (diameter $2 \mathrm{~mm}$ ) which were adhered to the bottom of culture dish by agar. Another group, the cells side of slides was placed up and put on the bottom of dish without capillaries. Then $9.50 \mathrm{ml}$ DMEM culture medium was added in the dishes. The slide in the place up group was respectively added $0.50 \mathrm{ml} 2 \mathrm{mg} / \mathrm{ml}$ free VCR, $30 \mathrm{~nm}$ VCR-Lip, and $100 \mathrm{~nm}$ VCR-Lip above the slides (Figure 13A). The slide in place down group was added $0.50 \mathrm{ml}$ $2 \mathrm{mg} / \mathrm{ml}$ free VCR, $30 \mathrm{~nm}$ VCR-Lip, and $100 \mathrm{~nm}$ VCRLip below slides (Figure 13B). After cultured for $24 \mathrm{~h}$, the cells were stained by Annexin-V/PI and the apoptosis was determination by FAC Scan flow cytometry.

\section{The different diffusion ability effect on cell uptake}

The fluorescent labeling Nile red lip liposome (NRLip) was prepared. The phospholipids proportion of NRLip was same with the blank $30 \mathrm{~nm}$ and $100 \mathrm{~nm}$ liposome, and then added $240 \mu \mathrm{L} 0.25 \mathrm{mg} / \mathrm{mL}$ Nile red fluorescein. The following formulation procedure was same as the 30 $\mathrm{nm}$ and $100 \mathrm{~nm}$ blank liposome. The final concentration of Nile red was $10 \mu \mathrm{L} / \mathrm{mL}$.

$0.5 \mathrm{~mL}$ HepG-2 cells suspension contained $4 \mathrm{x}$ $10^{4}$ cells was added into the laser confocal culture dish and incubated for $4 \mathrm{~h}$, then added $1.5 \mathrm{ml}$ DMEM culture medium. These cells were incubated overnight and discard the old culture solution. Each dish was added $1950 \mu \mathrm{L}$ DMEM and respectively $50 \mu \mathrm{L}$ free Nile, $30 \mathrm{~nm}$ NR-Lip and $100 \mathrm{~nm}$ NR-Lip. One group added the NR-Lip at the right above of the cells and the other group was added the NR-Lip away from the cells. The culture was incubated for $4 \mathrm{~h}$ and then using PBS wash the free Nile red and ploy formaldehyde fixed cell. The nucleus was stained by the Hochest 33342 and the cell uptake was observed by the laser scanning confocal microscope (UltraVLEW Vox, PerkvnElmer, USA).

\section{Diffusion in the tumor spheroids}

The prepared method of Cy5.5 fluorescent labeling liposome (Cy5.5-Lip) was same as the NR-Lip and the final concentration of Cy5.5 was $0.1 \mathrm{mg} / \mathrm{mL}$. 
$1 \times 10^{7}$ HepG-2 cells were added in the 6 well-plate and incubated the cells until they closely connected growth. The cell layer was divided into square with 1-2 mm side length by capillary. The small cells layer was fall off by digestion and transfer the cells into the $2 \%$ agar coated $96-$ well plate. The culture was incubated until the cells become tumor spheroids [44]. The free Cy5.5 (0.1 mg/mL), $30 \mathrm{~nm}$ Cy5.5-Lip (0.1 mg/mL) and $100 \mathrm{~nm}$ Cy5.5-Lip (0.1 mg/ $\mathrm{mL}$ ) was respectively diluted by DMEM culture medium. The dilution concentration of Cy5.5 in each group was $12.5 \mu \mathrm{L} / \mathrm{mL}$. The culture medium in the 96 -well plate was removed and added each diluted dyestuff $200 \mu \mathrm{L}$ in the 96well plate. The tumor spheroids were stained for $30 \mathrm{~min}$. Then the tumor spheroids were washed by PBS and fixed by $4 \%(\mathrm{w} / \mathrm{v})$ poly formaldehyde. The tumor spheroids was scanned at different layers $(10 \mu \mathrm{m} /$ layer $)$ by the laser scanning confocal microscope.

\section{In vivo anti-tumor efficacy}

The HepG-2 tumor-bearing female nude mice (18-22 g) were used to evaluate the anti-tumor efficacy in vivo [45]. Each mouse was subcutaneously injected with $0.2 \mathrm{ml}$ of cell suspension containing $1 \times 10^{7}$ HepG-2 cells on the root of right arm. When the volume of tumors was about 200-300 the mice were randomly divided into 3 treatment group and 1 control group $(n=6)$. Each mouse was treated every $72 \mathrm{~h}$ by tail vein injection $(1.25 \mathrm{mg} / \mathrm{kg}$ dose). The control group mice were given $0.625 \mathrm{~mL} / \mathrm{kg}$ normal saline. The tumor volume was measured every twoday and calculated the volume based on the equation (6). The mice were weighed every day during the period of treatment. After 16 days, the mice were sacrificed and weighed the tumor of each mice. The relative body weight and tumor volume was calculated as the following equations $(7,8)$.

$$
\mathrm{V}=\frac{\left(\mathrm{a} \times \mathrm{b}^{2}\right)}{2}
$$

Where a was indicated the length and $b$ was indicated the width of the tumor.

$$
\text { Relative body weight }=\frac{\mathrm{m}_{\mathrm{t}}}{\mathrm{m}_{0}}
$$

Where $m_{t}$ was the $t$ day's body weight and $m_{0}$ was the initial body weight of mice.

Relative tumor volume $=\frac{\mathrm{V}_{\mathrm{t}}}{\mathrm{V}_{0}}$

Where $\mathrm{V}_{\mathrm{t}}$ was the $\mathrm{t}$ day's tumor volume and $\mathrm{V}_{0}$ was the initial tumor volume of mice.

\section{Tissue distribution studies}

Firstly, we randomly divided 24 tumor bearing female nude mice (HepG-2) into three groups as the drug experimental groups ( $n=6$, free VCR group, $30 \mathrm{~nm}$ VCR-Lip group, and $100 \mathrm{~nm}$ VCR-Lip group) and a blank control group. After given the different formulations $0.5 \mathrm{~h}$ and $8 \mathrm{~h}$, three mice of each group were respectively sacrificed, and then the heart, liver, spleen, lung, kidney and tumor were removed to determination the VCR concentration in each tissue.

\section{Determination of the drug concentration of tissues}

Each tissue and triple normal saline was homogenized together. $10 \mu \mathrm{L}$ vinblastine sulfate $(200 \mathrm{ng} / \mathrm{mL})$ was added in $100 \mu \mathrm{L}$ tissue homogenate and $100 \mu \mathrm{L}$ tert-butylmethyl as internal standard solution, then the mixture was full mixed by vortex for $30 \mathrm{~s}$ and taken the centrifugal supernatant at $14,000 \mathrm{r} / \mathrm{min}$ for $5 \mathrm{~min}$. The supernatant was concentrated and the residue was dissolved in $100 \mu \mathrm{L}$ mobile phase.

The Agilent 1200-6410 Triple Quad LC/MS system was used to analyzed the sample of each tissue. Agela Venusil XBP C18 $(2.1 \mathrm{~mm} \times 50 \mathrm{~mm}, 3 \mu \mathrm{m})$ was used to separation the sample. The column temperature was held at 30 XBPAgimobile phase consisted was methanol-5mM ammonium acetate solution (solution A, 30:70, pH9.8, $\mathrm{V} / \mathrm{V}$ ) and methanol-5mM ammonium acetate solution (solution B, 90:10, pH9.8, V/V). The gradient elution program was showed in Table 3 and the sample volume was $10 \mathrm{~mL}$. The total analysis time was $5 \mathrm{~min}$.

The condition of mass spectrometry was as following: The detection of ions was used the positive ionization mode and the ion detection method were used multiple reaction-monitoring mode. The detection object was VCR $(\mathrm{m} / \mathrm{z}, 825.4 \longrightarrow 807.2)$ and internal standard $(\mathrm{m} / \mathrm{z}$, $811.3 \rightarrow 223.9)$. The Capillary voltage was $4000 \mathrm{~V}$ and the fragmentation voltage was $180 \mathrm{~V}$. The collision energy was $40 \mathrm{eV}$ for VCR and $45 \mathrm{eV}$ for internal standard. The nitrogen was used as drying gas and nebulizing gas. The gas flow was $9 \mathrm{~L} / \mathrm{min}$ [46] and the source temperature was $350{ }^{\circ} \mathrm{C}$.

\section{Statistical methods}

Descriptive statistics included the mean and standard error except particularly outlined. The statistical significance of the difference was tested using Student's t-test. "*" mean the $P$-value less than 0.05 which was considered to be significant and "***" mean the $P$-value less than 0.01 which was considered to be highly significant.

\section{CONCLUSION}

This study used the larger and smaller particle size liposome and the free drug or fluorescein to demonstrate the different diffusion ability in vitro and in vivo. All the results showed that the free drug have the strongest diffusion ability which could quickly diffused to uniformity in solution after dilution. For the drug loaded liposome, the diffusion ability of larger size liposome 
was weaker than the small one. To a certain extent, the particle size influenced the diffusion to the surface of the cells in vivo and in vitro. Thus influenced further inhibition of the tumor cells. The water soluble drugs had better diffusion ability in solution. However, the lower membrane permeability of them leaded to the poorer cytotoxicity when acting on tumor cells. And the lipid soluble drugs have the lower solubility in aqueous solution which leads to the lower concentration. Then the free drugs need larger dose to inhibit tumor cells comparing with the liposome encapsulated drugs with high drug loading ability, good water solubility and cell membrane penetration. On one hand the smaller liposome has better diffusion ability and higher particle concentration, which leads them easily reach tumor cells. On the other hand, they retain the characteristics of water solubility and cell penetration of liposome. In conclusion, reducing the particle size of liposome preserves the characteristics of liposome and strong diffusion ability, which results in the smaller liposome having sufficient quantity and ability to diffuse into tumor tissue from the tumor angiogenesis. These nanocarriers entering tumor tissue could also further play the active targeting effect if they are modified. Therefore, increasing the diffusion ability is the premise to enhance the active target and passive target effect of nano drug delivery system.

\section{Abbreviations}

VCR, vincristine

VCR-Lip, vincristine-liposome

Cy5.5-Lip, cyanine5.5 NHS ester labeled liposome

TEM, transmission electron microscope

MTT, methyl thiazolyl tetrazolium

RGB, red-green-blue

NR, Nile red

\section{ACKNOWLEDGMENTS}

This work was supported by the National Natural Science Foundation of China (Grant No. 81202466 and 81402874).

\section{CONFLICTS OF INTEREST}

The authors declare that no conflicts of interest exists.

\section{REFERENCES}

1. Dawidczyk CM, Kim C, Park JH, Russell LM, Lee KH, Pomper MG, Searson PC. State-of-the-art in design rules for drug delivery platforms: lessons learned from FDAapproved nanomedicines. J Control Release. 2014; 187: 133-144.
2. Shi C, Cao H, He W, Gao F, Liu Y, Yin L. Novel drug delivery liposomes targeted with a fully human anti-VEGF 165 monoclonal antibody show superior antitumor efficacy in vivo. Biomed Pharmacother. 2015; 73: 48-57.

3. Jiang L, Li L, He X, Yi Q, He B, Cao J, Pan W, Gu Z. Overcoming drug-resistant lung cancer by paclitaxel loaded dual-functional liposomes with mitochondria targeting and pH-response. Biomaterials. 2015; 490: 412-428.

4. Yang Z, Gong W, Wang Z, Li B, Li M, Xie X, Zhang H, Yang Y, Li Z, Li Y, Yu F, Mei X. A novel drugpolyethylene glycol liquid compound method to prepare 10-hydroxycamptothecin loaded human serum albumin nanoparticle. Int J Pharm. 2015; 490: 412-428.

5. Backer MV, Aloise R, Przekop K, Stoletov K, Backer JM. Molecular vehicles for targeted drug delivery. J Bioconjugate Chem. 2002; 13: 462-467.

6. Bruce Thurmond K II, McEwan J, Moro DG, Rice JR, Russell-Jones G, St John JV, Sood P, Stewart DR, Nowotnik DP. Targeted and non-targeted polymer drug delivery systems. Am Chem Soc. 2006; 137-154.

7. Bartneck M, Keul HA, Wambach M, Bornemann J, Gbureck U, Chatain N, Neuss S, Tacke F, Groll J, Zwadlo-Klarwasser G. Effects of nanoparticle surfacecoupled peptides, functional endgroups, and charge on intracellular distribution and functionality of human primary reticuloendothelial cells. Nanomedicine. 2012; 8: 1282-1292.

8. Herringson TP, Altin JG. Effective tumor targeting and enhanced anti-tumor effect of liposomes engrafted with peptides specific for tumor lymphatics and vasculature. Int J Pharm. 2011; 411: 206-214.

9. Bae YH, Park K. Targeted drug delivery to tumors: myths, reality and possibility. J Control Release. 2011; 153: 198-205.

10. Gao H, Yang Z, Zhang S, Cao S, Shen S, Pang Z, Jiang $X$. Ligand modified nanoparticles increases cell uptake, alters endocytosis and elevates glioma distribution and internalization. J Sci Rep. 2013; 3: 2534.

11. Kwon IK, Lee SC, Han B, Park K. Analysis on the current status of targeted drug delivery to tumors. J Control Release. 2012; 164: 108-114.

12. Kickhoefer VA, Han M, Raval-Fernandes S, Poderycki MJ, Moniz RJ, Vaccari D, Silvestry M, Stewart PL, Kelly KA, Rome LH. Targeting vault nanoparticles to specific cell surface receptors. ACS Nano. 2009; 3: 27-36.

13. Jo DH, Kim JH, Lee TG, Kim JH. Size, surface charge, and shape determine therapeutic effects of nanoparticles on brain and retinal diseases. Nanomedicine. 2015; 11: 1603-1611.

14. El-Naggar ME, El-Rafie MH, El-Sheikh MA, El-Feky GS, Hebeish A. Synthesis, characterization, release kinetics and toxicity profile of drug-loaded starch nanoparticles. Int $\mathrm{J}$ Biol Macromol. 2015; 81: 718-729. 
15. Chu KS, Hasan W, Rawal S, Walsh MD, Enlow EM, Luft JC, Bridges AS, Kuijer JL, Napier ME, Zamboni WC, DeSimone JM. Plasma, tumor and tissue pharmacokinetics of Docetaxel delivered via nanoparticles of different sizes and shapes in mice bearing SKOV-3 human ovarian carcinoma xenograft. Nanomedicine. 2013; 9: 686-693.

16. Wuelfing WP, Daublain P, Kesisoglou F, Templeton A, McGregor C. Preclinical dose number and its application in understanding drug absorption risk and formulation design for preclinical species. Mol Pharm. 2015; 12: 1031-1039.

17. Ling Z, Jiangou Z, Lingfu C. Albuminous dispersion, adsorption and permeation in blood capillary wall. J Nanjing Norm Univ Nat Sci. 2005; 8: 54-59.

18. Alinejad Y, Faucheux N, Soucy G. Preosteoblasts behavior in contact with single-walled carbon nanotubes synthesized by radio frequency induction thermal plasma using various catalysts. J Appl Toxicol. 2013; 33: 1143-1155.

19. Métin C, Denizot JP, Ropert N. Intermediate zone cells express calcium-permeable AMPA receptors and establish close contact with growing axons. J Neurosci. 2000; 20: 696-708.

20. Smith WF. Foundations of Materials Science and Engineering. McGraw-Hill, 3rd ed.

21. Achuthan S, Chung BJ, Ghosh P, Rangachari V, Vaidya A. A modified Stroker-Einstein for $A \beta$ aggregation. BMC Bioinformatics. 2011; 12: S13.

22. Chen SH, Wei SK. Modification of the Stokes-Einstein equation with a semiempirical microfriction factor for correlation of tracer diffusivities in organic solvents. Eng Chem Res. 2011; 50: 12304-12310.

23. Jain RK, Stylianopoulos T. Delivering nanomedicine to solid tumors. J Nat Rev Clin Oncol. 2010; 7: 653-664.

24. Greish K. Enhanced permeability and retention effect for selective targeting of anticancer nanomedicine: are we there yet? Drug Discov Today Technol. 2012; 9: 161-166.

25. Lieleg O, Baumgärtel RM, Bausch AR. Selective filtering of particles by the extracellular matrix: an electrostatic bandpass. Biophys J. 2009; 97: 1569-1577.

26. Holback H, Yeo Y. Intratumoral drug delivery with nanoparticulate carriers. J Pharm Res. 2011; 28: 1819-1830.

27. Yangmin W, Danying Q, Yonghua X, Lian C, Qi S; Quanzhou Medical College; Quanzhou Medical and Pharmaceutical Institute. Effect of total alkaloids from Selaginella involvens on transplantation tumor of hepatoma H22 in mice. Chin Arch Tradit Chin Med. 2016; 34: 2983-2986.

28. He K, Khorasani FB, Retterer ST, Thomas DK, Conra JC, Krishnamoorti R. Diffusive dynamics of nanoparticles in arrays of nanoposts. ACS Nano. 2013; 7: 5122-5130.

29. Liu L, Hitchens TK, Ye Q, Wu Y, Barbe B, Prior DE, Li WF, Yeh FC, Foley LM, Bain DJ, Ho C. Decreased reticuloendothelial system clearance and increased blood half-life and immune cell labeling for nano- and micronsized superparamagnetic iron-oxide particles upon pre-treatment with Intralipid. Biochim Biophys Acta. 2013; 1830: 3447-3453.

30. Peulen TO, Wilkinson KJ. Diffusion of nanoparticles in a biofilm. Environ Sci Technol. 2011; 25: 3367-3373.

31. Skaug MJ, Wang L, Ding Y, Schwartz DK. Hindered nanoparticle diffusion and void accessibility in a threeimensional porous medium. ACS Nano. 2015; 9: 2148-2156.

32. Cai LH, Panyukov S, Rubinstein M. Hopping diffusion of nanoparticles in polymer matrices. Macromolecules. 2015; 48: 847-862.

33. Lopez-Chavez A, Carter CA, Giaccone G. The role of KRAS mutations in resistance to EGFR inhibition in the treatment of cancer. Curr Opin Investig Drugs. 2009; 10: 1305-1314.

34. Li M, Al-Jamal KT, Kostarelos K, Reineke J. Physiologically based pharmacokinetic modeling of nanoparticles. ACS Nano. 2010; 4: 6303-6317.

35. Taurin S, Nehoff H, Greish K. Anticancer nanomedicine and tumor vascular permeability; where is the missing link? J Control Release. 2012; 164: 265-275.

36. Yang Y, Yang Y, Xie X, Wang Z, Gong W, Zhang H, Li Y, Yu F, Li Z, Mei X. Dual-modified liposomes with a twophoton-sensitive cell penetrating peptide and NGR ligand for siRNA targeting delivery. Biomaterials. 2015; 48: 84-96.

37. Li MY, Zhang H, Yang ZB, Mei ZG. Preperation and quality evaluation of vincristine sulfate thermosensitive liposomes. Inst Pharmacol Toxicol. 2014; 49: 1615-1619.

38. Mei X. Microcarrier Drug Delivery System, 2009, 137-141.

39. Zhang H, Wang ZY, Gong W, Li ZP, Mei XG, Lv WL. Development and characteristics of temperature-sensitive liposomes for vinorelbine bitartrate. Int J Pharm. 2011; 414: 56-62.

40. Dou YN, Zheng J, Foltz WD, Weersink R, Chaudary N, Jaffray DA, Allen C. Heat-activated thermosensitive liposomal cisplatin (HTLC) results in effective growth delay of cervical carcinoma in mice. J Control Release. 2014; 178: 69-78.

41. Yang Y, Yang Y, Xie X, Cai X, Zhang H, Gong W, Wang Z, Mei X. PEGylated liposomes with NGR ligand and heatactivable cell-penetrating peptideedoxorubicin conjugate for tumor-specific therapy. Biomaterials. 2014; 35: 4368-4381.

42. He C, Cai P, Li J, Zhang T, Lin L, Abbasi AZ, Henderson JT, Rauth AM, Wu XY. Blood-brain barrier-penetrating amphiphilic polymer nanoparticles deliver docetaxel for the treatment of brainmetastases of triple negative breast cancer. J Control Release. 2017; 246: 98-106.

43. Zhou Y, Li J, Zhang Y, Dong D, Zhang E, Ji F, Qin Z, Yang J, Yao F. Establishment of a physical model for solute diffusion in hydrogel: understanding the diffusion of proteins in poly (sulfobetaine methacrylate) hydrogel. J Phys Chem B. 2017; 121: 800-814.

44. Li XY, Zhao Y, Sun MG, Shi JF, Ju RJ, Zhang CX, Li XT, Zhao WY, Mu LM, Zeng F, Lou JN, Lu WL. 
Multifunctional liposomes loaded with paclitaxel and artemether treatment of invasive brain glioma. Biomaterials. 2014; 35: 5591-5604.

45. Nan L, Mingyu L, Wei G, Yang Yang YF, Hui Z, Xingguo M. Anti-tumor activity of long-circulation thermosensitive liposome-loaded vincristine. Inst Pharmacol Toxicol. 2016; 43: 491-495.
46. Bingsheng L, Wei G, Ying L, Mingyuan L, Guannan M, Xingguo M. Quantification of vincristine sulfate in dog plasma by HPLC-MS /MS and pharmacokinetics of vincristine sulfate thermosensitive liposomes in dogs. Inst Pharmacol Toxicol. 2015; 50: 705-708. 